Academic Platform Journal of Engineering and Science

\title{
LTE Ağlarda Remote-Host ile PG-W Arasındaki Kuyruk Yönetim Algoritmalarının Performans Analizi
}

\author{
${ }^{* 1}$ Muhammet Çakmak, ${ }^{2}$ Zafer Albayrak \\ ${ }^{1}$ Karabük Üniversitesi, TOBB Mesleki ve Teknik Bilimler Meslek Yüksek Okulu, Bilgisayar Teknolojileri Bölümü \\ muhammetcakmak@karabuk.edu.tr (iD \\ ${ }^{2}$ Karabük Üniversitesi, Mühendislik Fakültesi, Bilgisayar Mühendisliği Bölümü, zalbayrak@karabuk.edu.tr, \\ Araştırma Makalesi \\ Geliş Tarihi: 21.12 .2019 \\ Kabul Tarihi: 23.04 .2020
}

$\ddot{O} \mathbf{z}$

Mobil iletişiminin hızlı gelişmesiyle internet içeriğinin çoğu günümüzde hücresel ağlar ile sağlanmaktadır. Hücresel ağlarda yaşanan tıkanıklık sırasında kullanılan algoritmalar paket gecikmesi, kuyruk taşması ve darboğaz problemlerini çözmeye çalışmaktadırlar. LTE ağlarında remote-host ile PG-W dügümü arasındaki veri transferi yüksek hız gerektirmekte bu da hücresel ağın çalışma hızını doğrudan etkilemektedir. Doğru bir kuyruk yönetim algoritmasının seçilmesi LTE hücresel ağı için kritik bir önem kazanmaktadır. Bu çalışmada LTE ağlarında remote-host ile PG-W arasında çalışan aktif kuyruk yönetim algoritmaları olan RED, CoDel, Pie ve pFIFO'nun performanslarının, uçtan uca ortalama verim, gecikme ve paket düşürme oranları üzerindeki etkisi karşılaştırmalı olarak incelenmiştir ve sonuçları değerlendirilmiştir.

Anahtar Kelimeler: Ns-3, Simülatör yazılımı, RED, CoDel

\section{Performance Analysis of Queue Management Algorithms Between Remote-Host and PG-W in LTE Networks}

\author{
*1Muhammet Çakmak, ${ }^{2}$ Zafer Albayrak \\ ${ }^{1}$ Karabuk University, TOBB Vocational and Technical Sciences Vocational High School, Computer Technologies, \\ muhammetcakmak@karabuk.edu.tr \\ ${ }^{2}$ Karabuk University, Faculty of Engineering, Computer Engineering, \\ zalbayrak@karabuk.edu.tr
}

\begin{abstract}
With the rapid development of the mobile communication, most of the internet content is provided by cellular networks. The algorithms used during the congestion in cellular networks try to solve the problem of queue overflow and bottleneck. In the LTE network, the data transfer between the remote host and the PG-W directly affects the operating speed of the cellular network. Choosing an active queue management algorithm is critical to the LTE cellular network. In this study, the effect of the performance of RED, CoDel, Pie and PFIFO, which are active queue management algorithms operating between Remote Host and PG-W, on LTE network on end-to-end average throughput, latency and packet dropping rates were evaluated comparatively and the results were evaluated.
\end{abstract}

Keywords: Ns-3, Simulator Software, RED, CoDel

\section{GíRiş}

Hücresel ağlar mobil cihazların artışıyla son yıllarda çok hızlı bir değişim göstermiştir. Cisco raporuna göre 2022 yılında; mobil ağların kullanımı toplam IP trafiğinin $\% 80$ 'nin temsil edecektir ve akıllı telefonlar mobil internet trafiğinin \%90'nını sağlayacaktır [1]. İnternetin hızla yaygınlaşması, hücresel ağların kullanım oranları ve alanlarını genişletmekte ihtiyacını doğurmuştur. Bununla birlikte hücresel ağlarda daha az gecikme ve paket kaybı ihtiyaçlarının karşılanması daha fazla önem kazanmaktadır. Bu gereksinimler, LTE (Long Term Evolution) standardina dayalı 4G hücresel şebekelerinin tamamen paket anahtarlamalı yapısıyla sağlanmaktadır [2].

*Sorumlu Yazar: Karabük Üniversitesi, TOBB Mesleki ve Teknik Bilimler Meslek Yüksek Okulu, Bilgisayar Teknolojileri Bölümü muhammetcakmak@karabuk.edu.tr 
LTE, Genişband Kod Bölmeli Çoklu Erişim (Wideband Code Division Multiple Access) (WCDMA) sistemlerine oranla daha yüksek bir verimlilik ve düşük gecikme süresi imkanı sağlamakta, büyük ölçüde geliştirilmiş sistem kapasitesi, kapsama alanı sağlayan yeni bir hava arayüzü ve radyo erişim ağı sunmaktadır [3]. Bu iyileştirmeler, geçmişten günümüze kadar kullanılan $1 \mathrm{G} / 2 \mathrm{G} / 3 \mathrm{G}$ sistemlere kıyasla, LTE üzerinde mobil hücresel ağlarda artan beklentilere yol açmaktadır. [4].

LTE'nin kaynakların kullanımında; yüksek kullanıcı veri hızı, sistem kapasitesinin iyileştirilmesi, gecikme süresinin azaltılması ve kapsama alanının verimli bir şekilde kullanılması sağlanmalıdır. LTE ağının veri trafiğinde, ağın yürütme kapasitesini aşan bir artış, Evolved Node B (eNodeB)'deki kullanıcı kuyruklarında paketlerin birikmesine sebep olmaktadır. Bu durum da eNodeB'deki kuyruk boyutunun küçüklüğü, fazla gelen paketlerin tamponda birikerek kuyruktan düşmesi ve kuyruk taşması sorunlarına neden olmaktadır [5].

LTE ağlarında Packet Gateway (P-GW) ile remote-host arasındaki trafik kontrolü sistem performansına doğrudan etki etmektedir. Remote-host'tan P-GW'ye gönderilen paketlerin eNodeB'deki tamponlarda birikmesi darboğaz ve kuyruk taşması (paket düşmesi) sorunlarına yol açmaktadır. eNodeB'lerde yaşanan dar boğaz, eNodeB'ye bağlanan, bağlanmak isteyen ve başka bir hücresel alana geçmek isteyen UE'ler için performans sorunları doğurmaktadır.

LTE'de sıkışıklık oluştuğunda yüksek verim ve düşük gecikmeyi sağlamak için önerilen çalışmalar, sunulan iyileştirmenin tek bir yönüne odaklanmakta, siteme olan bütüncül etkisini ve katkısını değerlendirmemektedir. Bu çalışmada remote-host ile P-GW arasında çalıştırılan algoritmaların performansları uçtan uca verim, gecikme ve paket düşürme oranları gibi parametrelerle bütüncül olarak değerlendirilmiş ve her bir algoritmanın avantaj ve dezavantajları incelenmiş ve karşılaştırılmalı olarak değerlendirilmiştir.

Çalışmanın devamında; ikinci bölümünde literatürdeki çalışmalar incelenmiş, üçüncü bölümde gerçek bir ağ yapısının simüle edilebilmesi için kullanılacak materyal ve yöntem ortamı gösterilmiştir. Dördüncü bölümde simülasyon sonuçları ve çıktılarının değerlendirilmesi sağlanmıştır ve beşinci bölümde ise çalışmanın sonuçlarının değerlendirilmesi yapılmıştır.

\section{2. İLGILLI ÇALIŞMA}

Kablolu ve kablosuz ağlarda, ağ tıkanıklığı ve bununla ilgili performans sorunlarını ele almak için araştırma toplulukları ve geliştiriciler ağ performansının artırılması için birçok kuyruk yönetim algoritması önermişlerdir. $\mathrm{Bu}$ algoritmalar ağ kullanımı, paket kaybı ve farklı trafik yükleri için uyarlana bilirlik gibi özelliklerin bazılarını veya tamamını iyileştirmeyi amaçlamıştır. $\mathrm{Bu}$ yapılar, kayıp tabanlı tıkanıklık kontrolü [8], [9] gecikme tabanlı tıkanıklık kontrolü [10], [11] ve hız tabanlı tıkanıklık kontrolü [12], [13] gibi sorunlara çözümler önermişlerdir. Önerilen bu Aktif Kuyruk Yönetim Algoritmaları (Active Queue Management) (AQM)'ler kapalı yöntem [14], [15], açık yöntem [16], [17] ve gecikme bazlı yöntemler [18], [19] ile sorunları çözmeye çalışmışlardır.

Lakshmikantha vd. kablolu bir ağda gerçek ve sanal temelli işaretleme şemalarını/algoritmalarını karşıllaştırmıştır. Tasarladıkları Sanal Kuyruk (Virtual Queue) (VQ) tabanlı algoritmanın Gerçek Kuyruk (Real Queue) (RQ) tabanlı algoritma karşısında bozulmalara karşı dayanıklılık ve düşük kuyruk gecikmesine sahip olması açısından daha iyi sonuçlar verdiğini gözlemlemişlerdir [20].

Uydu ağları için önerilen AVQRED (Adaptive Virtual Queue RED) algoritması Sanal tabanlı Kuyruk (Adaptive Virtual Queue) (AVQ) ve RED'in karşılaştığı uyumsuz kuyruk salınımları ve global senkronizasyon problemlerine çözüm getirerek ağın kararlılığını artırmıştır. Bu kapsamda bağlantı ile ilgili bozulmaları azaltmaya çalışan PEP'ler, arabellekte biriken kuyruklarla karşılaştığında sorun yaşamaktadır. Bu sorunları adaptif bir kuyruk sistemi ile kaynakları paylaştırarak çözüm sağlamıştır [21].

LTE'de eNodeB için RLC katmanında değişken trafik yüklerinde tampon sıkışıklığı ve paket düşmesinin önlenmesi için RED'deki varyans değerinin ayarlanmasıyla çalışan akıllı AQM olan smRED (smart-RED) ile paket programcılarının tek hücre ve çok hücrede devretme (handover) ve devretme olmadan iş hacmi/verim, gecikme ve sapma değerleri üzerine etkisi incelenmiştir. RED’in ayarlanan varyans değeri i düşük ve yüksek yük durumlarında farklı değerler alarak RCL tamponlarında biriken paketlerin düşmesini etkilemiştir [23].

Paket Programlayıcı Sıkışıklık Geri Besleme Mekanizması (Packet Sheduling Congestion Identification and Feedback Mechanisms) ile kuyruk taşmasından kaçınmak ve kuyruktaki gecikmeleri azaltmak için kuyruk taşması ve paket gecikme tahmininin erken tanımlanması, eNodeB' deki ağ tıkanıklığının tahmini, sıkışıklık penceresi boyutunu ayarlamak için kaynak düğüme bildirimde bulunulması iyileştirilmeleri bir düzen şeklinde yapılmıştır. Paketin QoS değeri ile paketin TCP yada UDP olarak tanımlanmasi sağlanmış ve dolu kuyrukların tahmini için ortalama bir değer hesaplanarak paket düşüşlerine dayanıksız olan TCP için düşük, UDP için ise yüksek düşük aralıkları belirlenmiş böylece paket düşüşünden kaçınılmıştır. Gönderici tıkanıklık penceresi ağın trafik durumuna göre yüksek, orta ve düşük olarak ayarlanarak eNodeB'deki kuyruk taşmasının önüne geçilmeye çalışılmıştır [24].

Bu çalışmada, NS-3 ağ simülatörünü kullanarak LTE ağlarında her bir algoritmanın performans analizine odaklandık. Ayrıca, her algoritmanın kendi parametrelerini koruyarak ve farklı Kullanıcı Ekipmanı (User Equipment) (UE) Numaralarına göre simülasyon çalışması yapılmıştır. 


\section{MATERYAL VE YÖNTEM}

LTE ağlarında remote-host tarafından üretilen paketler $\mathrm{P}$ GW düğümünden eNodeB aracılığ Hücresel ağ içerisindeki mobil kullanıcılar eNodeB'ye hava arayüzü üzerinden bağlanmaktadır. LTE ağlarında yaşanan paket düşüşleri, düşürülen paketlerin yeniden iletilmesi ve ağ kaynaklarının gereksiz kullanımına sebep olur. eNodeB'deki kullanıcı kuyruklarındaki yaşanan kuyruk taşması problemini azaltmak ve uygun bir şekilde çözmek için aktif kuyruk yönetimi algoritmalarından yararlanılmaktadır. $\mathrm{Bu}$ çalışmada sırasıyla LTE mimarisinin genel yapısını, P-GW düğümünün işlevini ve aktif kuyruk yönetim algoritmaları incelenmektedir.

\subsection{LTE Mimarisi}

LTE'nin temel amacı, esnek bant genişliği, yüksek veri hızı, düşük gecikme süresi ve optimize edilmiş paket tabanlı radyo erişim teknolojisi sağlamaktır. Aynı zamanda, ăg mimarisi, kesintisiz hareketlilik ve yüksek hizmet kalitesi ile paket anahtarlamalı trafiği desteklemek için tasarlanmıştır.

LTE sistemi, Sistem Mimarisi Evrimi (System Architecture Evolution) (SAE) olarak bilinen bir mimariye dayanmaktadır. LTE, yüksek hızda veri ve sinyal iletimi ve sorunsuz bir hareket desteği sağlamaktadır. Şekil 1'de gösterildiği gibi, esas olarak çekirdek ağ yani Evrimleşmiş Paket Çekirdeği (Evolved Packet Core) (EPC) ve EvolvedEvrensel Karasal Radyo Erişim Ağı (Evolved Universal Terrestrial Access Network) (E-UTRAN) olarak adlandırılan iki bölümden oluşmaktadır [25].

Gelişmiş paket çekirdeği IP multimedya alt sistemine (IP Multimedia Subsystem) (IMS) bağlanır. Ev Abone Sunucusu (Home Subscriber Server) (HSS), EPC' de veri tabanı görevi gören ana IMS veri tabanıdır. EPC'nin üç ana fonksiyonel birimi vardır: Mobilite Yönetimi Varlığı (Mobility Management Entity) (MME), Servis A ̆g Geçidi (Serving Gateway) (S-GW) ve Paket Veri Ağ Geçidi (Packet Data Network Gateway) (P-GW). MME, ağa bağlantı kurulduktan sonra kullanıcı mobiletesinden, kullanıcı ekipmanının LTE'deki geçiş, takip ve çağrı işlemlerinin ele alınmasından sorumludur [26].

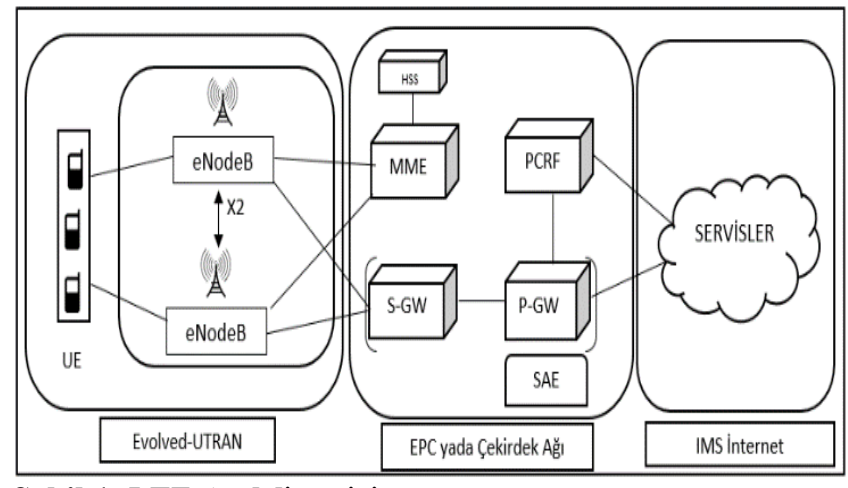

Şekil 1. LTE Ă̆ Mimarisi
SGW'nin ana işlevi, LTE düğümleri arasında kullanıcı veri paketlerini yönlendirmek ve diğer 3GPP teknolojileri arasında geçişi yönetmektir. PGW, LTE ağını Internet'in geri kalanıyla birbirine bağlayan bir fonksiyona sahiptir. LTE erişim ağı UE (son kullanıcı) ve eNodeB (baz istasyonu) olarak iki tür düğüm barındırır.

\subsection{P-GW Düğümü}

Ağ yönetimi için güvenlik ve kolaylık sağlamak amacıyla, yalnızca üçüncü katmanla ilgili olan geleneksel İnternetten farklı olarak, P-GW, 3GPP'nin LTE' ye eriştiği sahnede uygulama katmanı protokolü olarak GTPv2'yi kullanarak uygulama katmanı protokolünü içerir. SAE, ve her kullanıcı için S5 / S8 arayüzünde Paket Veri Protokolü (PDP) ile iletişim kurar [22]. Harici ağdan veri akışı P-GW düğümüne girdiğinde, servis veri paketinin hangi kullanıcıya gönderileceğini ve hangi servis veri paketinin gönderileceğini belirleyen PDP içerik taraması yapmaktadır. Burada, kuyruk yönetimi elde etmek için uygulama katmanına taşınır. Uygulama Katmanı Kuyruk Yönetim Algoritması Şekil 2' de gösterilmektedir. Uygulama katmanında, düşük paket önce PDP içerik eşlemesini gerçekleştirir ve bu grubun QoS Sinıf Tanımlayııı (QoS Class Identifier) (QCI) 'sini belirler ve sonra grupları farklı QCI'ye göre farklı sıralara yerleştirir. [27].

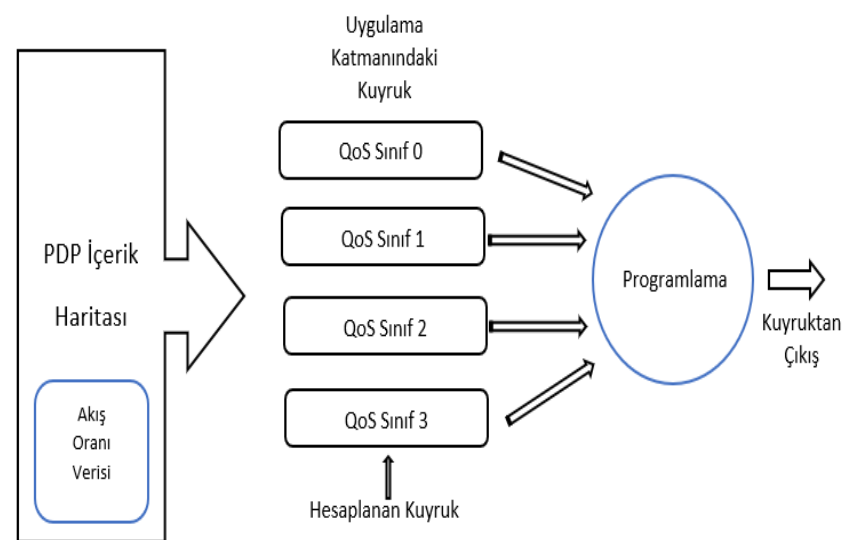

Şekil 2. Uygulama Katmanı Kuyruk Yönetim Algoritması

\subsection{Aktif Kuyruk Yönetim Algoritmaları}

RED (Random Early Detection), Floyd ve arkadaşları tarafından ortaya konulan ilk AQM algoritma çalışmasıdır. RED paket anahtarlamalı ağlarda tıkanıklıktan kaçınmak için ortalama kuyruk büyüklügünü kullanarak ă̆ tıkanıklığını hesaplamaya çalışır [28]. RED algoritması, kuyruk boyutunu dört parametre ile yönetmektedir. $\mathrm{Bu}$ parametreler kuyruk uzunluğu, maksimum eşik (Maxth), minimum eşik (Minth), ve maksimum olasılık (Pmax). Algoritma, ortalama bir kuyruk büyüklüğünü korumaya yönelik çalışmaktadır. Paket düşme olasılık değeri (Pd), Minth ile Maxth değerleri arasında bulunan ortalama kuyruk büyüklük değişimi ile sıfır değeri ile Pmax değeri arasında doğrusal olarak değişim göstermektedir. Ortalama kuyruk boyut değeri Maxth'ı aşarsa, gelen tüm paketler düşürülmektedir [29]. RED algoritması, paket düşmesi 
nedeniyle oluşan tıkanıklık yapısını kontrol edebilmektedir, çünkü paket düşürme mekanizması, geçmiş değerlerin hareketli ortalamasına göre işlem yapmaktadır.

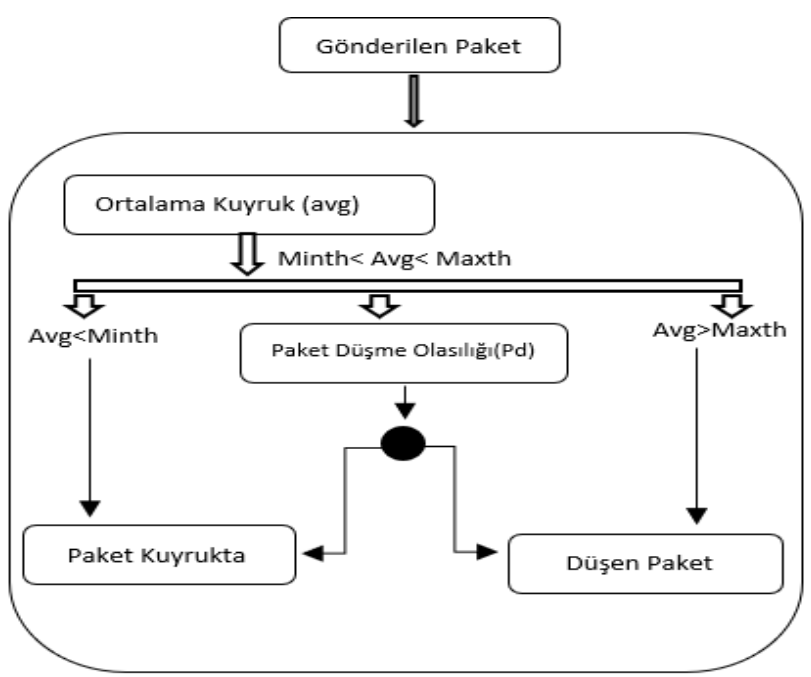

Şekil 3. RED Algoritmasının Akış Diyagramı

Ağdaki darboğaz problemini çözmek için geliştirilen CoDel (Controlled Delay), Nichols ve Jacobson tarafindan ortaya konuldu. Tamponlara gelen paketler normal koşullar altında tıkanıklık durumunda düşürülmekte ancak tamponun yüksek boyutlu olması durumunda sürekli kuyruğa eklenen paketler, paket gecikmesine neden olmaktadır [30].

RED ve CoDel algoritmaları bağlantı kullanımı, verim ve adalet karmaşıklığı performansları bakımından karşılaştırılmıştır. RED'in aksine CoDel kuyruk büyüklüğü ve ortalamas1, kuyruk gecikmesi ve düşme oranı gibi parametrelerden bağımsızdır. CoDel, paket gecikmesi süresini kullanarak ağdaki tıkanıklığı tespit eder. Paket iletim süresi belirlenen hedef değeri aştı̆̆ında CoDel tarafından tıkanıklık tespit edilir. T1kanıklığın tespitinden sonra kuyruktaki yığılmayı önlemek için paket düşürülmesi amaciyla sinyal gönderilir [31].

pFIFO (Packet limited First In, First Out queue), FIFO algoritması temel alınarak oluşturulmuş bir aktif kuyruk yönetim algoritmasıdır. A $\breve{g}$ trafiği için farklı kanallar göz önüne alınarak sınıflandırılır. Yüksek öncelikli trafik daha önce işlenmektedir. Temel amacı farklılaştırılmış hizmet sınıflarının desteklenmesi amacıyla basit bir yöntem olarak tasarlanmıştır [32]. pFIFO'nun avantajı düşük hesap yükleri ve gerçek zamanlı uygulamalar da üretilen trafik iletimidir. En önemli problemlerinden birisi çok fazla sayıda yüksek öncelikli trafik bulundurmasıdır. Ağdaki en önemli problem yüksek öncelikli trafiğin hacminin fazla olması, düşük öncelikli trafik için ayrılan tampon alanının azalması ve taşmanın meydana gelmesidir. Bu durum ağda paket düşmesine ve ağın yavaşlamasına sebep olmaktadır.

PIE (Proportional Integral Controller Enhanced) (Geliştirilmiş Orantılı Entegre Kontrolör), ağdaki gecikmeyi etkili bir şekilde kontrol etmek için tasarlanmıştır. PIE' de ortalama kuyruğa girme oranı, hareket halinde olmayan kuyruğa göre tahmin edilir. Hı, mevcut gecikmeyi hesaplamak için kullanılmaktadır. Daha sonra, periyodik olarak gecikme, düşme olasılığını hesaplamak için kullanılır. Son olarak, paket hedefe vardığında, bu olasılığa göre bir paket düşürülür (veya işaretlenir). PIE, gecikme eğilimine bağlı olarak olasılıkta ayarlamalar yapar. Alfa ve beta, düşme olasılığ 1 artışını kontrol etmek için seçilen statik olarak seçilmiş parametrelerdir ve kontrol teorik yaklaşımları ile belirlenir. Alfa, mevcut ve hedef gecikme arasındaki sapmanın olasılığı nasıl değiştirdiğini belirler. Beta, gecikme eğilimine bağlı olarak ek ayarlamalar yapmaktadır. PIE zamana duyarlı performansını artırmak için tasarlanmıştır ve yüksek bağlantı kullanımını korurken etkileşimli trafik ve ağ istikrarı sağlamaya çalışmaktadır [33]. Kontrol parametrelerini küçük artışlarla uyarlayarak, dengesizliğe yol açan büyük salınımlardan kaçınılmasını sağlamaktadır.

\section{SIMMÜLASYON ÇALIŞMASI}

$\mathrm{Bu}$ bölümde, LTE ağı için ağ topolojisi ve sistem parametreleri belirlendikten sonra uçtan uca ortalama verim, gecikme ve paket kaybı açısından simülasyon sonuçları değerlendirilmiştir.

\subsection{A A Topolojisi ve Sistem Parametresi}

Ağdaki trafiği deneysel olarak gözlemlemenin en kolay ve en etkili yollarından biri simülasyon yöntemidir. $\mathrm{Bu}$ yöntemle ağ düğümleri, bağlantılar ve ağ trafiği gerçek dünyaya benzer olacak şekilde tasarlanarak farklı durumların simülasyonları kolayca yapılabilir. OPNET, OMNET++ gibi simülatörlerle karşılaştırıldığında eğitim ve araştırma amaçlı kullanım amacıyla geliştirilen Ns3, GNU ve GPLv2 lisansları altında kullanılan ücretsiz açık kaynak kodlu ayrık olay tabanlı performansı ile önce çıkan bir yazılımdır [34]. $\mathrm{Bu}$ sebeple kullanılan algoritmalara ait karşılaştırmaları göstermek için çalışmamızda Ns3 simülatörü kullanılmıştır. Uçtan uca LTE ağı oluşturmak için LTE / EPC Network Simulator ve Analysis (LENA) modülünü [35] kullanılmıştır. LENA modülü, EPC ve Evolved E-UTRA dahil olmak üzere gerçek bir LTE sisteminin tüm önemli öğelerine sahiptir. Ns3'teki LTE modeli, uyarlamalı modülasyon ve kodlama, Ortogonal Frekans Bölmeli Çoklu Erişim (Orthogonal Frequency-Division Multiple Access) (OFDMA), Hibrit Otomatik Tekrar İsteği (Automatic repeat Request) (ARQ) vb. gibi LTE standardının çeşitli yönlerinin ayrıntılı bir şekilde uygulanmasını sağlar. Ns3 uygulaması, 3GPP LTE'nin ve çeşitli TCP sürümlerinin ayrıntılı özelliklerini kapsamaktadır. Bu nedenle, simülasyonda elde edilen sonuçlar gerçek bir sistemde neler olduğunu temsil edebilmektedir. LTE ağlarında Şekil 4'te gösterildiği gibi önce tek hücreli veya Şekil 5 'de gösterildiği gibi çok hücreli çok kullanıcı bir ağ yapısı oluşturulmaktadır. 


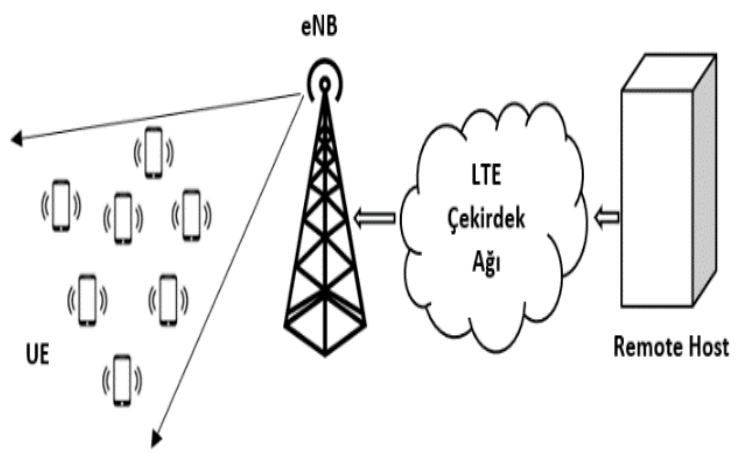

Şekil 4. Tek Hücreli LTE Ağ Topolojisi

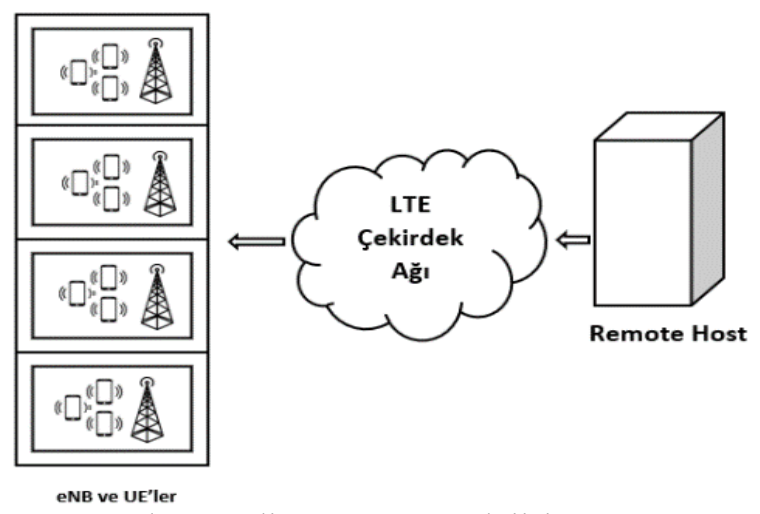

Şekil 5. Çok Hücreli LTE Ağ Topolojisi

$\mathrm{Bu}$ çalışmada gerçek duruma uygun bir LTE ağ yapısının oluşturulabilmesi için çok hücreli çok kullanıcılı bir ağ yapısı seçilmiştir. Böylece elde edilen veriler gerçek sisteme daha çok benzemektedir. Deneysel ortam için, 3 eNodeB (baz istasyonu) ve sirasiyla $10,20,30$ ve 40 UE (mobil kullanıcı) bir sistem kurgulanmıştır. Her bir kullanıcı sayısı için RED, Codel, PIE ve pFIFO algoritmaları ayrı ayrı çalıştırılmıştır. Elde edilen sonuçlar da her bir aktif kuyruk yönetim algoritması; ortalama uçtan uca verim, ortalama uçtan uca gecikme ve paket kayıp oranları bakımından teker teker karşılaş̧ırılmıştır. Simülasyon ortamı için Tablo 1'deki simülasyon değeri kullanılmıştır.

Tablo 1. Simülasyon Değerleri

\begin{tabular}{|l|l|}
\hline Simülasyon Parametresi & Değer \\
\hline Trafik Kaynağı Sayısı & $10-40$ \\
\hline Veri Hızı & $100 \mathrm{Gbps}$ \\
\hline TCP Trafik Tipi & TcpNewReno \\
\hline Handover/Devretme Algoritması & A3Rsrp \\
\hline Hareketlilik Tipi & RandomWalk2D \\
\hline Toplam Simülasyon Zamanı & 100 sn \\
\hline Simülasyon Başlama Zamanı & $0.1 \mathrm{sn}$ \\
\hline A ̆ Topolojisi & Çoklu Hücre \\
\hline eNodeB arası Mesafe & $250 \mathrm{~m}$ \\
\hline
\end{tabular}

Simülasyon ortamı için önce 3 eNodeB ve 10 adet UE sisteme rasgele olarak yerleştirilmiştir. eNodeB'ler birbirine X2 arayüzü ile bağlanmıștır. Ve UE'lerin hareketi esnasında eğer bir hücresel yer değiştirme olursa, bu değişimle ilgili varsayılan olarak A3Rsrp algoritması çalışmaktadır. Her bir eNodeB'nin arası 250 metre olarak belirlenmiştir. Simülasyonda TCP trafiği için, en çok tercih edilen ve performans olarak etkili olan TcpNewReno varsayılan olarak çalışmaktadır. Simülasyonda veri trafiği 0.1 saniyeden itibaren başlamakta ve simülasyon 100 saniye sürmektedir. UE'lerin sayısı sirasıyla 20,30 ve 40 olacak şekilde artırılmakta ve her bir yeni durum için elde edilen sonuçlar grafiksel olarak gösterilmektedir.

\subsection{Uçtan Uca Ortalama Verim}

Şekil 6'da aktif kuyruk yönetim algoritmalarının çalıştırılması ile elde edilen uçtan uca ortalama verim değerinin kullanıcı sayısına göre değişimi gösterilmiştir. 10 mobil kullanıcı ile simülasyona başlanmış ve kullanıcı sayısı onar onar artırılmıştır. 3 eNodeB için 10 kullanıcı bir simülasyon ortamı ile elde edilen değerler yüksek iken, kullanıcı sayısının artması ile elde edilen ortalama uçtan uca çıkış verimi değerleri doğal bir azalma göstermiştir. CoDel algoritması, yüksek kullanıcı grupları arasında uçtan uca verim değeri açısından en iyi performansı göstermiş̧tir. Sirasıyla diğer en iyi performansı veren algoritmalar, RED, Pie ve pFIFO olarak sıralanmaktadır. CoDel algoritması, paket düşüşlerinin erken tespiti ve paketlerin kuyruğa girme süresine göre işlem yapması sebebiyle en iyi sonucu verir. Kuyruk dolduktan sonra gelen paketleri birakan pFIFO algoritması, tüm algoritmalar arasında en kötü sonucu verdi. Bu pFIFO'nun yüksek trafik için en savunmasız algoritma olduğunu göstermektedir.

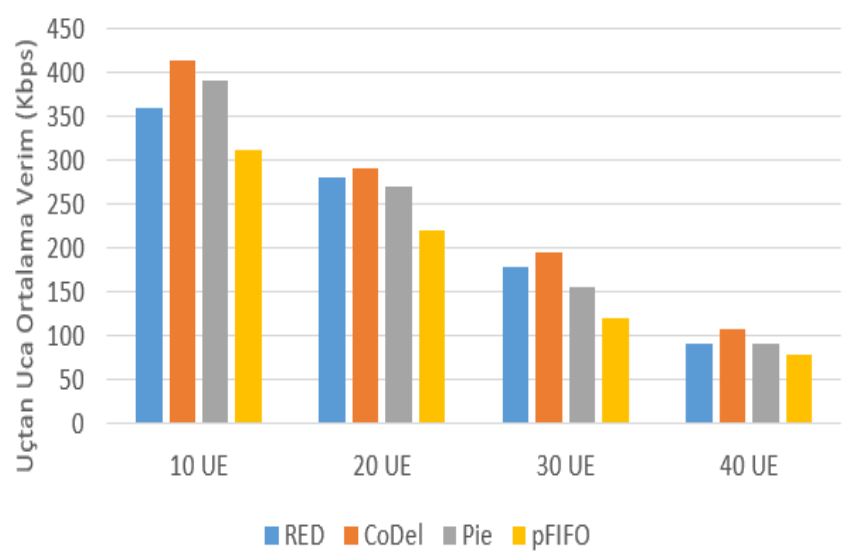

Şekil 6. Uçtan Uca Ortalama Verimin Karşılaştırılması

\subsection{Uçtan Uca Ortalama Gecikme}

Şekil 7, kullanıcının sayılarına göre uçtan uca ortalama gecikme sürelerini göstermektedir. Uçtan uca gecikmeyi, PG-W yönlendiricisinden eNodeB düğümüne gelen paketlerdeki modülasyon, kodlama, paket oluşturma süresi gibi parametreler uçtan uca gecikmeyi önemli ölçüde etkilemektedir. CoDel, kuyruğu yönetmek için kuyruğun 
boyutunu kullanmaz, paketlerin kuyruğa girme süresini kullanır. $\mathrm{Bu}$ da CoDel algoritmasının paket düşürme değerinin az olmasını ve buna bağlı olarak da uçtan uca verim değerinin diğer algoritmalara göre yüksek olmasını sağlamaktadır çünkü fazla paket düşürülmesi sitemin çıkış değerini olumsuz etkilemektedir. CoDel algoritması en düşük paket kaybı oranına sahip olmasıyla, uçtan uca verimde en iyi performansı göstermektedir. Sirasıyla bu algoritmayı RED, Pie ve PFIFO takip etmektedir.

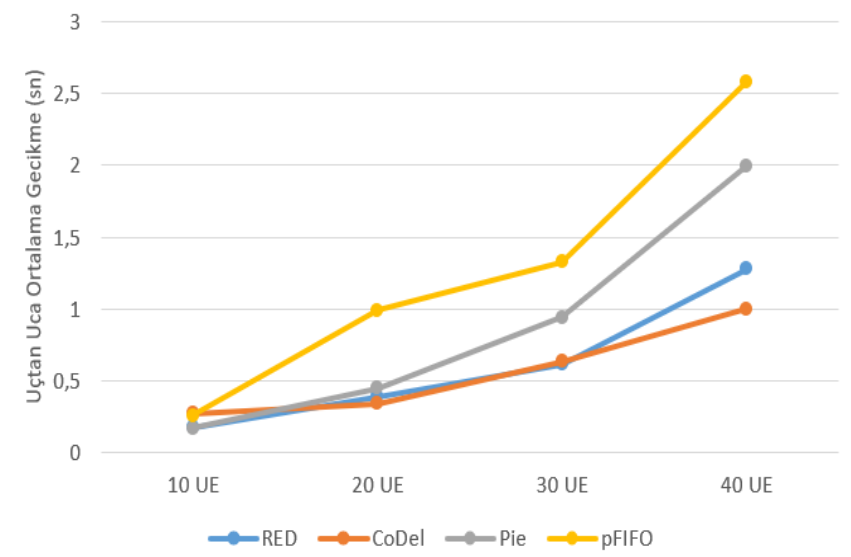

Şekil 7. Uçtan Uca Ortalama Gecikmelerin Karşılaştırılması

\subsection{Paket Kayıp Oranı}

Şekil 8, kullanıcının sayılarına göre paket kayıp oranlarını göstermektedir. Paket kaybının fazla yaşanması paket kaybının telafisi için geçirilen süreler ve sistemin tekrar kararlı hale gelmesi gibi nedenlerden dolayı LTE ağlarında performansin olumsuz olarak etkilenmesine neden olmaktadır. Paket kayıp oranlarına bakıldığında PFIFO algoritması tüm kullanıcı gruplarında en yüksek paket düşürme değerine sahip olmasıyla, ağ performansını olumsuz yönde etkileyen algoritmadır. CoDel, tüm kullanıcı gruplarında en düşük paket kayıp oranı ile en güçlü aktif yönetim algoritması olarak öne çıkmaktadır.

CoDel, tüm simülasyon sonuçlarına göre, ortalama uçtan uca verim, ortalama uçtan uca gecikme ve paket oranı ile en güçlü aktif kuyruk yönetim algoritması olarak çalışmaktadır. Sirasiyla CoDel'i RED, Pie ve PFIFO izlemektedir. RED'in kuyruğa almadaki problemi, farklı boyutlarda ağ bant genişlikleri için parametrelerin ayarlanmasına ihtiyaç duymasıdır, CoDel ise bu problemi çözmektedir. CoDel, ayarlarının değiştirilmesine gerek kalmadan herhangi bir bant genişliği boyutu aralığında iyi çalışır. CoDel, kuyruğu yönetmek için kuyruğun boyutunu kullanmaz, paketlerin kuyruğa girme süresini kullanır. Hedef adlı bir kuyruk süresi belirler ve kuyruk süresi bu hedefin altına düştüğünde paketleri düşürmez. RED algoritmasının güçlü yönü ise paket düşürürken kuyruk uzunluğunu kontrol eder ve minimum ve maksimum değerler arasında bulunan eşik değerine göre paketi düşürüp düşürmeyeceğine karar verir. $\mathrm{Bu}$ yönüyle CoDel'den sonra RED en iyi sonucu üretmektedir. PFIFO ve Pie kuyruk doluluğunu referans alması sebebiyle daha basit bir kontrol mekanizması ile çalışmaktadır.

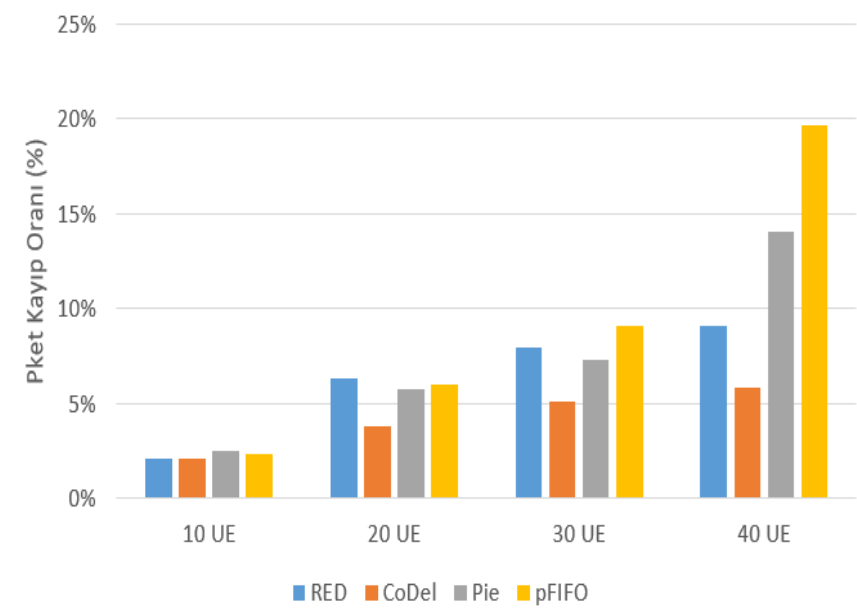

Şekil 9. Paket Kayıp Oranlarının Karşılaştırılması

\section{SONUÇ}

LTE ağlarında, PG-W dügüumünden eNodeB'ye gelen paketlerin tamponda birikmesi sebebiyle sistemde darboğaz yaşanmaktadır. LTE ağlarının yükünün artmasıyla uçtan uca verim, gecikme ve paket düşürme değerleri olumsuz yönde etkilenmektedir. Simülasyon sonuçlarına göre en başarılı algoritma CoDel algoritmasıdır. Sirasıyla RED, Pie ve PFIFO bu algoritmayı takip etmektedir. CoDel, ayarlarının değiştirilmesine gerek kalmadan herhangi bir bant genişliği boyutu aralığında iyi çalışır. CoDel, kuyruğu yönetmek için kuyruğun boyutunu kullanmaz, paketlerin kuyruğa girme süresini kullanır. Bu da CoDel paket düşürme değerinin az olmasını ve buna bağlı olarak da uçtan uca verim ve gecikme değerlerinin az olmasını sağlamaktadır. RED algoritması paket düşürürken ortalama kuyruk değerini hesaplar ve bu değer minimum ve maksimum eşik değerleri arasında olduğu sürece paket düşürülmesine izin vermez ancak RED algoritması yüksek yük durumlarında maksimum eşik aşılırsa tüm paketleri düşürebilir bu da sistem performansına olumsuz olarak etkileyebilir. Pie ve PFIFO algoritmaları ise paket düşürülmesi için kuyruk uzunluklarını referans alır bu ise sınırlı kaynakların olduğu bir sistemde elverişli bir yöntem değildir.

\section{KAYNAKÇA}

[1] Cisco and S. Jose, "Cisco visual networking index (VNI) global mobile data traffic,” Ca, Usa, pp. 3-5, 2019, [Online]. Available: https://www.cisco.com/c/en/us/solutions/collateral/serviceprovider/visual-networking-index-vni/white-paper-c11738429.html.

[2] S. Y. Hui and K. H. Yeung, "Challenges in the Migration to 4G Mobile Systems," IEEE Commun. Mag., vol. 41, no. 12, pp. 54-59, 2003, doi: 10.1109/MCOM.2003.1252799.

[3] D. Astély, E. Dahlman, A. Furuskär, Y. Jading, M. Lindström, and S. Parkvall, "LTE: The evolution of mobile 
broadband," IEEE Commun. Mag., vol. 47, no. 4, pp. 44-51, 2009, doi: 10.1109/MCOM.2009.4907406.

[4] M. Çakmak and Z. Albayrak, "A Review: Mobile Communication Past, Present and Future," 2018 International Conference on Advanced Technologies, Computer Engineering and Science (ICATCES), pp. 141$145,2018$.

[5] M. Rinne and O. Tirkkonen, "LTE, the radio technology path towards 4G," Comput. Commun., vol. 33, no. 16, pp. 1894-1906, 2010, doi: 10.1016/j.comcom.2010.07.001.

[6] C. Applications, "an Active Queue Management," vol. 14, no. 1, pp. 65-72, 2009.

[7] Santhi V. and Natarajan A.M., "Performance Analysis of Active Queue Management Algorithms," Inf. Sci. Comput., vol. 3, no. 1, pp. 230-232, 2009, [Online]. Available: sathyabama.com/archives/iisc_abstract.php?id=36.

[8] B. Qureshi, M. Othman, S. Subramaniam, and N. A. Wati, "QTCP: Improving Throughput Performance Evaluation with High-Speed Networks," Arab. J. Sci. Eng., vol. 38, no. 10, pp. 2663-2691, 2013, doi: 10.1007/s13369012-0483-z.

[9] P. J. Argibay-Losada, K. Nozhnina, A. SuárezGonzález, C. López-García, and M. Fernández-Veiga, "Loss-based proportional fairness in multihop wireless networks," Wirel. Networks, vol. 20, no. 5, pp. 805-816, 2014, doi: 10.1007/s11276-013-0644-3.

[10] N. Iya, N. Kuhn, F. Verdicchio, and G. Fairhurst, "Analyzing the impact of bufferbloat on latency-sensitive applications," IEEE Int. Conf. Commun., vol. 2015-Septe, no. ii, pp. 6098-6103, 2015, doi: 10.1109/ICC.2015.7249294.

[11] L. S. Brakmo and L. L. Peterson, "TCP Vegas: End to End Congestion Avoidance on a Global Internet," IEEE J. Sel. Areas Commun., vol. 13, no. 8, pp. 1465-1480, 1995 , doi: 10.1109/49.464716.

[12] A. Abdelsalam, M. Luglio, C. Roseti, and F. Zampognaro, "TCP Wave: A new reliable transport approach for future internet," Comput. Networks, vol. 112, pp. 122-143, 2017, doi: 10.1016/j.comnet.2016.11.002.

[13] S. Mascolo, C. Casetti, M. Gerla, M. Y. Sanadidi, and R. Wang, "TCP Westwood: Bandwidth estimation for enhanced transport over wireless links," Proc. Annu. Int. Conf. Mob. Comput. Networking, MOBICOM, pp. 287297, 2001.

[14] S. Floyd and V. Jacobson, "Random Early Detection Gateways for Congestion Avoidance," IEEE/ACM Trans. Netw., vol. 1, no. 4, pp. 397-413, 1993, doi: $10.1109 / 90.251892$.

[15] M. P. Tahiliani, K. C. Shet, and T. G. Basavaraju, "CARED: Cautious Adaptive RED gateways for TCP/IP networks," J. Netw. Comput. Appl., vol. 35, no. 2, pp. 857864, 2012, doi: 10.1016/j.jnca.2011.12.003.

[16] S. Floyd, "TCP and explicit congestion notification," ACM SIGCOMM Comput. Commun. Rev., vol. 24, no. 5, pp. 8-23, 1994, doi: 10.1145/205511.205512. [17] M. Casoni, C. A. Grazia, M. Klapez, and N. Patriciello, "How to avoid TCP congestion without dropping packets: An effective AQM called PINK," Comput. Commun., vol. 103, pp. 49-60, 2017, doi: 10.1016/j.comcom.2017.02.010.

[18] C. Control, "BBR : Congestion-Based," Commun. ACM, vol. 60, no. 2, pp. 58-66, 2017, doi: 10.1145/3009824.

[19] K. Nichols and V. Jacobson, "Controlling queue delay," Queue, vol. 10, no. 5, pp. 1-15, 2012, doi: 10.1145/2208917.2209336.

[20] A. Lakshmikantha and G. Engineering, "Real and Virtual Queue based Active Queue Management Schemes',' pp. 266-271.

[21] D. J. Byun and J. S. Baras, "Adaptive virtual queue random early detection in satellite networks," Lect. Notes Electr. Eng., vol. 44 LNEE, pp. 63-82, 2009, doi: 10.1007/978-0-387-71787-6_4.

[22] Q. L. Qiu, C. Jian, L. Di Ping, and X. Z. Pan, "Hierarchy virtual queue based flow control in LTE/SAE," 2nd Int. Conf. Futur. Networks, ICFN 2010, no. 2008, pp. 78-82, 2010, doi: 10.1109/ICFN.2010.8.

[23] A. Paul, H. Kawakami, A. Tachibana, and T. Hasegawa, "Effect of AQM-Based RLC Buffer Management on the eNB Scheduling Algorithm in LTE Network," Technologies, vol. 5, no. 3, p. 59, 2017, doi: 10.3390/technologies5030059.

[24] A. N.D. and R. A., "Avoiding queue overflow and reducing queuing delay at eNodeB in LTE networks using congestion feedback mechanism," Comput. Commun., vol. 146, no. May, pp. 131-143, 2019, doi: 10.1016/j.comcom.2019.07.015.

[25] G. Gómez, Q. Pérez, J. Lorca, and R. García, "Quality of service drivers in LTE and LTE-A networks," Wirel. Pers. Commun., vol. 75, no. 2, pp. 1079-1097, 2014, doi: 10.1007/s11277-013-1409-0.

[26] B. Clerckx, A. Lozano, S. Sesia, C. van Rensburg, and C. Papadias, "3GPP LTE and LTE-Advanced," EURASIP J. Wirel. Commun. Netw., vol. 2009, no. 1, p. 472124, 2009, doi: 10.1155/2009/472124.

[27] F. Cheng, X. Hang, and H. Lei, "A Congestion Control Scheme for LTE / SAE," vol. 51, no. Iccsit 2011, pp. 400-405, 2012, doi: 10.7763/IPCSIT.2012.V51.67.

[28] S. Floyd and V. Jacobson, "Random Early Detection for Congestion Avoidance," IEEE/ACM Trans. Netw., vol. 1, no. 4, pp. 397-413, 1993.

[29] F. B. Dergisi, "Evaluation of Active Queue Management," pp. 123-140, 2005.

[30] A. Arora, L. Bhambhu, and I. I. C. Management, "Evaluation of Active Queue Management Algorithms," vol. 2, no. 4, pp. 197-203, 2014.

[31] M. Çakmak and Z. Albayrak, "A Review: Active Queue Management Algorithms in Mobile Communication", 2018 International Conference on Advanced Technologies, Computer Engineering and Science (ICONCS), pp. 180 184, 2018.

[32] M. M. Hamdi, S. A. Rashid, M. Ismail, M. A. Altahrawi, M. F. Mansor, and M. K. Abufoul, "Performance Evaluation of Active Queue Management Algorithms in Large Network," ISTT 2018 - 2018 IEEE 4th Int. Symp. Telecommun. Technol., no. May 2019, 2018, doi: 10.1109/ISTT.2018.8701716. 
[33] K. S. Shravya, S. Murali, and M. P. Tahiliani, "Implementation and evaluation of Proportional Integral Controller Enhanced (PIE) algorithm in ns-3," ACM Int. Conf. Proceeding Ser., vol. Part F1321, pp. 9-16, 2016, doi: 10.1145/2915371.2915385.

[34] Z. Albayrak and, C. Torun "Recent LTE Simulation
Tools," International Conference on Engineering and Natural Sciences, pp. 2007-2014, 2016.

[35] G. Piro, N. Baldo, and M. Miozzo, "An LTE module for the ns-3 network simulator," Proc. 4th Int. ICST Conf. Simul. Tools Tech., 2011, doi: 10.4108/icst.simutools.2011.245571. 